\title{
An increase of cereal intake as an approach to weight reduction in children is effective only when accompanied by nutrition education:
} a randomized controlled trial

\author{
Jorge L Rosado*1,2, María del R Arellano ${ }^{\dagger 1}$, Karina Montemayor ${ }^{\dagger 1}$, \\ Olga P García ${ }^{\dagger 1}$ and María del C Caamaño ${ }^{\dagger 1,2}$
}

Address: ${ }^{1}$ Facultad de Ciencias Naturales, Universidad Autónoma de Querétaro, Querétaro México and ${ }^{2}$ CINDETEC, México

Email: Jorge L Rosado* - jlrosado@avantel.net; María del R Arellano - roare2001@hotmail.com; Karina Montemayor - carim7@yahoo.com.mx; Olga P García - opgarcia@yahoo.com.mx; María del C Caamaño - mccaamano@hotmail.com

* Corresponding author †Equal contributors

Published: 10 September 2008

Nutrition Journal 2008, 7:28 doi:|0.1|86/|475-289|-7-28

This article is available from: http://www.nutritionj.com/content/7/I/28

(c) 2008 Rosado et al; licensee BioMed Central Ltd.

This is an Open Access article distributed under the terms of the Creative Commons Attribution License (http://creativecommons.org/licenses/by/2.0), which permits unrestricted use, distribution, and reproduction in any medium, provided the original work is properly cited.
Received: 23 April 2008

Accepted: 10 September 2008

\begin{abstract}
Background: The main emphasis of dietary advice for control of obesity has been on reducing dietary fat. Increasing ready to eat cereal (RTEC) consumption could be a strategy to reduce fat intake and increase carbohydrate intake resulting in a diet with lower energy density.

Objectives: I. To determine if an increase in RTEC intake is an effective strategy to reduce excess body weight and blood lipids in overweight or at risk of overweight children. 2. To determine if a nutrition education program would make a difference on the response to an increase in cereal intake. 3) To determine if increase in RTEC intake alone or with a nutrition education program has an effect on plasma lipid profile.

Experimental design: One hundred and forty seven overweight or at risk of overweight children (6-12 y of age) were assigned to one of four different treatments: a. One serving of $33 \pm 7 \mathrm{~g}$ of RTEC for breakfast; b. one serving of $33 \pm 7 \mathrm{~g}$ of RTEC for breakfast and another one for dinner; c. one serving of $33 \pm 7 \mathrm{~g}$ of RTEC for breakfast and a nutrition education program. d. Non intervention, control group. Anthropometry, body composition, physical activity and blood lipids were measured at baseline, before treatments, and 12 weeks after treatments.

Results: After 12 weeks of intervention only the children that received $33 \pm 7 \mathrm{~g}$ of RTEC and nutrition education had significantly lower body weight $[-1.01(-1.69,-0.34)], p<0.01]$, lower BMI $[-0.95(-1.7 I,-0.20), p<0.01]$ and lower total body fat $[-0.71 \mathrm{I}(-1.7 \mathrm{I}, 0.28), \mathrm{p}<0.05]$ compared with the control group $[1.19(0.39,1.98), 0.01(-0.38$, $0.41), 0.44(-0.46,1.35)$ respectively]. Plasma triglycerides and VLDL were significantly reduced [-20.74 $(-36.44$, $5.05),-3.78(-6.9 \mathrm{I},-0.64)$ respectively, $\mathrm{p}<0.05]$ and $\mathrm{HDL}$ increased significantly $[6.6 \mathrm{I}(2.15, \mathrm{II} .08), \mathrm{p}<0.0 \mathrm{I}]$ only in this treatment group. The groups that received I or 2 doses of RTEC alone were not significantly different to the control group.
\end{abstract}

Conclusion: A strategy to increase RTEC consumption, as a source of carbohydrate, to reduce obesity is effective only when accompanied by nutrition education. The need for education could be extrapolated to other strategies intended for treatment of obesity.

Trial Registration: Australian New Zealand Clincial Trial Registry. Request no: ACTRNI 2608000025336 


\section{Background}

Recent estimates suggest that up to 1.7 billion people worldwide are overweight or obese, making it one of the biggest health threats facing world's population. Obesity lies at the other end of malnutrition scale and is becoming a public health problem in developing countries as well. Over 115 million people suffer from obesity related problems in developing countries [1]. In Brazil and Colombia for example, 36 and $41 \%$ of the population respectively is overweight. Prevalence of obesity in Mexico was unknown until recently [2,3]: about $26 \%$ of children between 5 and 12 years of age and $35 \%$ of the adult women are obese. The high prevalence of obesity in the Mexican population must be contributing to the increment in chronic diseases that has been observed in recent years [4]. Health officials and academia have recognized the need for urgent preventive measures to stop this accelerating trend.

Several studies have identified an excessive intake of dietary fat as a major mechanism for increasing the amount of body fat in humans and experimental animals. Diets with a high fat content are energy dense [5]. Thus, reduction of dietary fat as a treatment for obesity has been a widely used approach. A number of trials with low-fat diets have demonstrated the effectiveness of such recommendation [6-8]. In addition to weight loss, low fat diets help maintain low cholesterol and triglyceride levels in blood, reduce leptin concentration, increase adiponectin and reduce insulin resistance, and decrease cardiovascular and diabetes risk $[9,10]$.

An increase in the carbohydrate to fat ratio is associated with the reduction in energy density of the diet [11]. A dietary recommendation to increase cereal consumption is a possible approach to improve the carbohydrate to fat ratio. Studies in adult men and women have demonstrated that an increase in dietary carbohydrates from ready-to-eat cereals (RTEC) or other foods, even in the lack of an advice to reduce fat, is a potentially effective approach for weight reduction $[5,12,13]$.

The objectives of the study were: 1) To determine if an increase in cereal intake by consuming RTEC, among overweight or at risk of overweight children is an effective treatment to reduce excess body fat, 2) To determine if the inclusion of a nutrition education program in addition to an increase in carbohydrate intake has an effect on body weight and body fat, and 3) To determine if an increase in RTEC intake alone or with a nutrition education program has an effect on plasma lipid profile.

\section{Methods}

\section{Subjects and place of study}

Children were eligible if they had a BMI for age $>85 \%$ and were attending elementary school with an age range from
6 to 12 years. In order to detect children as being overweight or at risk of overweight, 6 elementary schools of the city of Queretaro were randomly selected and invited to participate; 5 schools accepted participation. Parents of all children from $1^{\text {st }}$ to $6^{\text {th }}$ grade were invited to a session where details of the study were explained, including benefits and potential risks of child participation. Parents of 905 children accepted voluntarily to participate in an initial screening to detect overweight or at risk of overweight children. Weight and height were determined in all children at their schools. Children were weighed without sweater or jacket and without shoes using an electronic scale (SECA, Erecta 844, Hamburg, Germany) to the nearest $1 \mathrm{~g}$. Height was measured using portable stadimeters (SECA, Bodymeter 208, Germany). Children with a BMIfor-age above the $85^{\text {th }}$ percentile were enrolled in the experimental study. According to the Center for Disease Control and Prevention (CDC) references, a child at risk of overweight is defined as having a BMI-for-age between the $85^{\text {th }}$ and $95^{\text {th }}$ percentile of the CDC growth charts [14]. Overweight is defined as a BMI-for age at or above the $95^{\text {th }}$ percentile (14).

Of the 905 children initially screened, 17\% had a BMI-forage percentile between $85 \%$ and $95 \%$, and $18 \%$ had a BMI-for-age percentile equal or above $95 \%$. Of these overweight and at risk of overweight children, 256 accepted to participate in a longitudinal controlled study, from which 178 children completed the study. Lost to follow-up was mainly due to the children's lack of compliance to the study protocol. The sample size of 178 subjects that completed the study accomplishes the expected sample size with an alpha error of 0.05 and a beta error of 0.2 , to detect a BMI expected difference of $1 \mathrm{~kg} / \mathrm{m}^{2}$, with an expected standard deviation of BMI change of $1 \mathrm{~kg} / \mathrm{m}^{2}$. Blood samples were taken from children if parents agreed to the procedure. Of the 178 subjects that completed the study, a blood sample was obtained from 129 children. Children included in the study were healthy volunteers with no apparent disease apart from being overweight.

\section{Experimental groups and treatments}

Children were randomly assigned to one of four different treatments. They were stratified into 4 groups with similar age, height and BMI percentile and same gender, in order to create groups with similar baseline characteristics. A randomization of treatments was done to each group with a computer generating random number list. The randomization was done at a central office by someone who did not have contact with the children or their parents. Children in group 1 consumed one serving of $33 \pm 7 \mathrm{~g}$ of RTEC (Kellogg's de Mexico, Querétaro, Mexico) at breakfast. Children in group 2 consumed two servings of $33 \pm 7 \mathrm{~g}$ of RTEC, one at breakfast and another serving at dinner. Children in group 3 consumed one serving of $33 \pm 7$ 
grams of RTEC and in addition, both children and mothers received a nutrition education guide that contained recommendations for healthy eating. Children in group 4 were involved in the study and had no treatment. Follow up in all groups was for 12 weeks.

To allow for variety in the diet, children consumed from 4 different types of RTEC: a corn based RTEC (Corn Flakes ${ }^{\circledast}$, Kellogg Company Mexico), a pre-sweetened corn based RTEC (Zucaritas ${ }^{\circledast}$, Kellogg Company Mexico), a pre-sweetened corn based, chocolate flavored RTEC (Choco Zucaritas $^{\varpi}$, Kellogg Company Mexico), and a pre-sweetened rice based, chocolate flavored RTEC (ChocoKrispis ${ }^{\circledast}$, Kellogg Company Mexico). These RTEC were chosen because of the high consumption among children. The children were allowed to choose from the 3 pre-sweetened RTEC only for 3 days in one week and were not allowed to repeat. The remaining four days children consumed from corn-based cereal only. The mean nutrient composition of RTEC per serving was as follows: $165 \mathrm{Kcal}(712 \mathrm{KJ}), 5.8 \mathrm{~g}$ of protein, $0.5 \mathrm{~g}$ total fat, and $35 \mathrm{~g}$ of carbohydrates. The RTEC was consumed with $250 \mathrm{~mL}$ of cold skimmed milk in a bowl with a spoon. Compliance was recorded by weekly interviews to the parents.
A nutrition education guide was prepared by one of us (RA) based on general recommendations for obese individual developed by Perez-Lizaur and Marvan [15] which included recommendations for the whole family and recommendations for the child. The nutrition education program included 12 sessions (one per week) that were given at school to the children's parents (usually the mother), both in oral and written form. The dietary recommendations were given by a nutritionist. Practice of the recommendations mentioned above was monitored weekly during RTEC delivery at the school by asking the parents if they had any difficulty following the nutrition education guide. Table 1 shows a summary of the major aspects included in the nutrition education guide. As part of the education guide, a sample menu was provided so that parents could use it to plan their meals at home and for school.

Children in all four groups were evaluated for anthropometry, body composition, physical activity, and blood lipids at the beginning of the study before treatments and after 12 weeks with each respective treatment.

\section{Anthropometry, body composition and blood lipids}

Anthropometric measures included weight and height and were done as described above. Standardization in

Table I: Summary of the nutrition education guide used in one treatment group

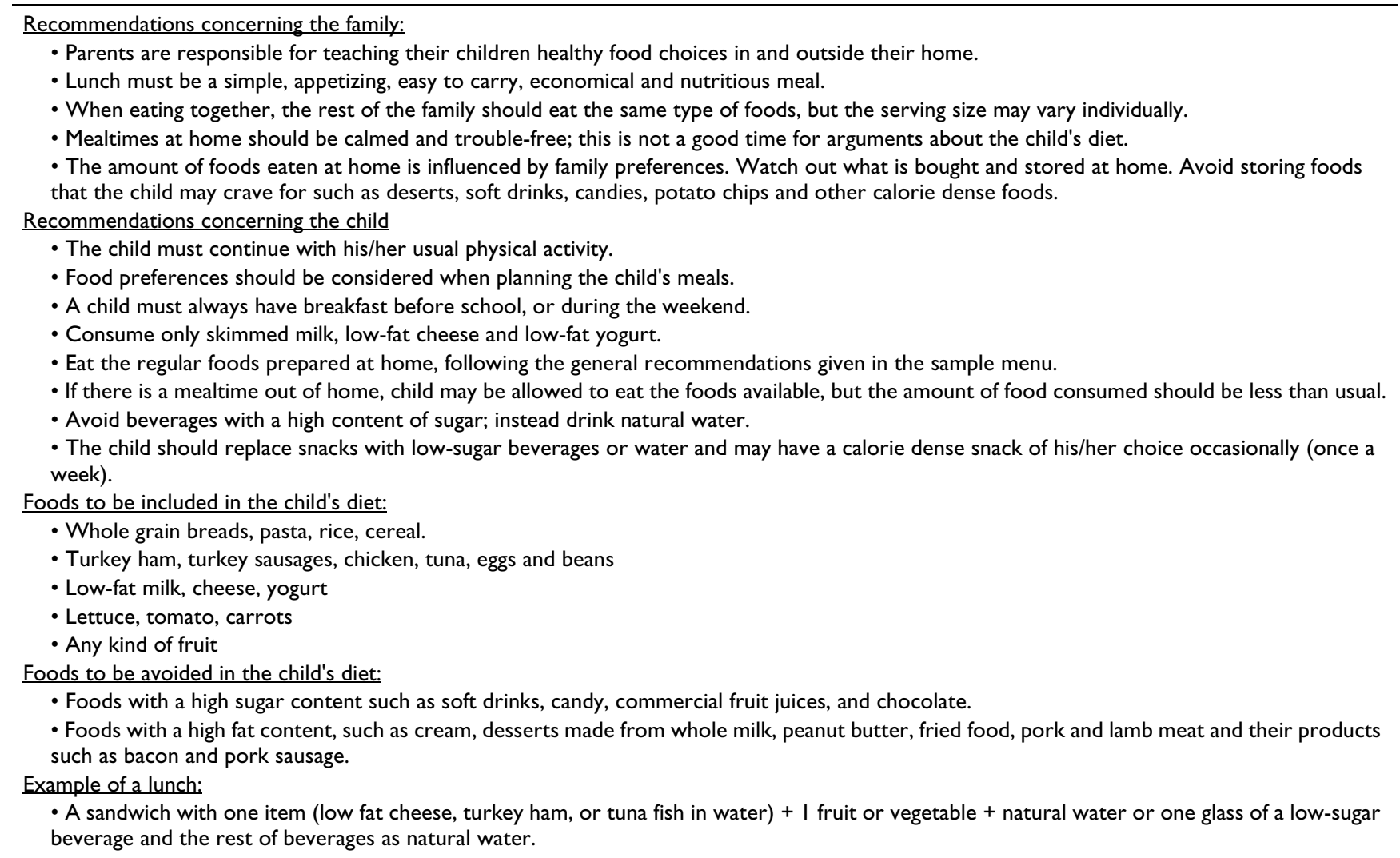


height and weight measures was done following standard procedures recommended by the World Health Organization [16]. Each child was evaluated by the same observer at basal and post-treatment. Body composition analysis was carried out by bioelectrical impedance using a conductance measurement apparatus (BIA 101, RJL Systems, Clinton TWP, MI). The apparatus was calibrated everyday before measures were carried out. Children were laid down in a bed placed in a quiet room inside the school, apart from where the rest of the measurements took place. Electrodes were placed on the left foot and right hand, after cleaning the area with alcohol. Children were asked to remain calm and not to move for the duration of evaluation.

A fasting blood sample was drawn from every child at basal and after 12 weeks of treatment. Children in all schools were asked to attend at 8 in the morning. Mother and child were instructed that the child should not have any food after 9 p.m. on the night before. Both mother and child were asked before the blood sample was taken if the child had fasted. Blood samples were centrifuged at 1800-2000 rpm during 15 minutes and plasma was stored at $-20^{\circ} \mathrm{C}$ until analysis. Biochemical analysis in plasma samples included triglycerides, total cholesterol and HDL cholesterol and were done using a commercial kit (Sera-Pak Kit Bayer Diagnostics, France).

\section{Physical activity evaluation}

Physical activity of all children was evaluated by asking the child's mother to fill out a questionnaire at the beginning of the study and 12 weeks after treatment began. The questionnaire asked to recall different physical activities normally carried out by children throughout the week as well as their duration. This questionnaire has been validated and applied in previous studies [17]. The outcome of the questionnaires showed the time spent performing different activities during the week. Time of each type of activity was transformed into Metabolic Equivalent units (Mets/hr), which is the ratio of the metabolic rate during the physical activity to the resting metabolic rate, according to the compendium of physical activities from the Prevention Research Center of the University of South Carolina [18]. For data analysis, physical activities were grouped into intense, moderate and low depending on Mets/hr spent as follows: Low $=0$ to 3 Mets/hr, Moderate $=3$ to 6 Mets $/$ hr and Intense $=6$ or more Mets $/ \mathrm{hr}$.

\section{Data analysis}

Percent fat and fat free mass were calculated from the reactance and resistance values obtained in the bioimpedance analysis using the equation suggested by Kottler et al. (1996) [19]. LDL and VLDL were calculated from total cholesterol, HDL and triglycerides concentrations [20]. BMI and BMI percentile were calculated in Epi-Info v.3.3.2. Treatment effect was measured as the change on anthropometric and biochemical determinations within initial and final measures and mean change among groups comparison. Partial measurements were analyzed to confirm validity of initial and final measurements. Within effects were carried out with a paired T-Test. Between groups effect in lipids and anthropometry changes was observed with a one-way ANOVA to compare unadjusted changes and with a univariate general linear model adjusted for baseline value, gender and interactions in case they resulted significant and the school random effect. Physical activity analysis was evaluated as the final evaluation controlled for baseline value, gender and the school random effect. Treatments' pairwise comparisons were tested with the least significant difference test [21]. Additionally, an analysis of variance and a chi square test was carried out to compare baseline age, anthropometry and gender of subjects included in the analysis versus children that had missing data and were not included in the analysis. Statistical analyses were performed using the software SPSS, V.9.0 (Chicago, IL).

\section{Results}

Children were recruited from October to December 2002 and the fieldwork was from January to June 2003. The statistical analyses considered all children that had initial and final measurements in an intention to treat basis. Only one child that had an extreme weight final value was excluded from analysis. The participants' flow chart is shown in figure 1 . Age, gender and height were not different between children included and children excluded from the analysis. Characteristics of subjects in the experimental groups at the beginning of the study are shown in table 2. Changes in weight, BMI and body composition are shown in Table 3. After 12 weeks of intervention there was a significant increase in body weight in the two RTEC groups and in the control group, only the group that had RTEC plus nutrition education had no increment in body weight. In analysis of variance, children that consumed one serving of RTEC and had nutrition education had a difference in unadjusted weight change of $2.03 \mathrm{~kg}$ compared with children in the control group $(\mathrm{p}<0.01)$. Body weight change in the RTEC and nutrition education group adjusted for gender, school and baseline body weight was also significantly different from the control $(\mathrm{p}<0.001)$ and the other two treatment groups $(p<0.01)$. Unadjusted and adjusted changes in body weight with both treatments with RTEC alone were not statistically different from the control group. BMI reduced significantly only in the group of children that received RTEC and nutrition education ( $\mathrm{p}<0.01)$; children in this group had an unadjusted change in mean BMI of $0.64 \mathrm{~kg} / / \mathrm{m}^{2}$ higher than the control group ( $<<0.01)$. This group's adjusted change in BMI was also statistically greater than control $(\mathrm{p}<0.01)$ and the other two treatments with RTEC only $(\mathrm{p}<0.05)$. 


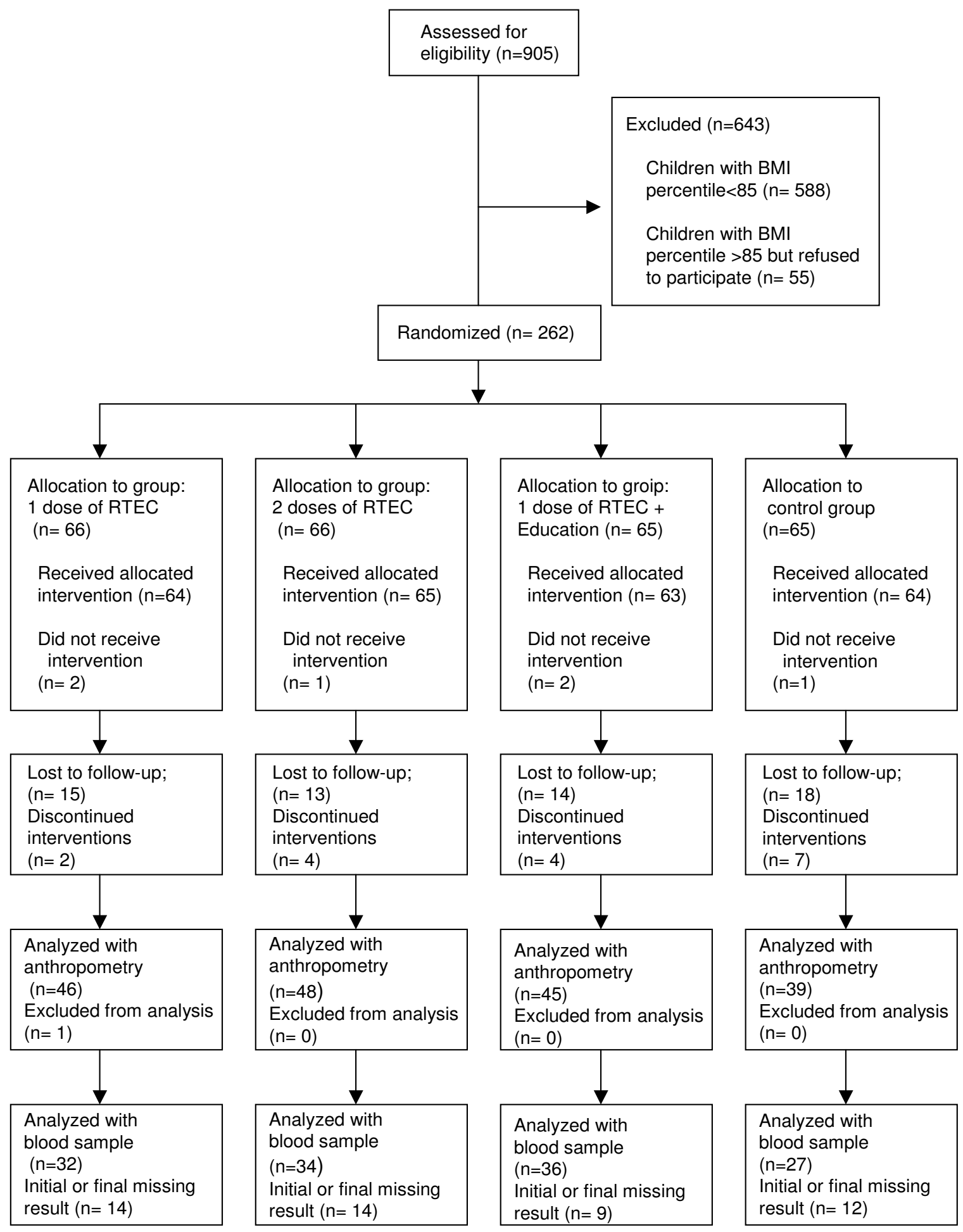

Figure I

Flow-chart. 
Table 2: Characteristics of subjects in experimental groups at baseline *†

\begin{tabular}{|c|c|c|c|c|}
\hline & I dose of RTEC & 2 doses of RTEC & I dose of RTEC + Nutrition education guide & Control \\
\hline $\mathrm{N}$ & 46 & 48 & 45 & 39 \\
\hline Males \% & 56.4 & 40.5 & 47.5 & 51.6 \\
\hline Females \% & 43.6 & 59.5 & 52.5 & 48.4 \\
\hline Age $(m)$ & $110.3 \pm 19.7$ & $109.3 \pm 18.9$ & $107.8 \pm 18.8$ & $110.1 \pm 18.9$ \\
\hline \multicolumn{5}{|l|}{ Anthropometry: } \\
\hline Weight (Kg) & $47.0 \pm 12.9$ & $47.7 \pm 12.7$ & $46.4 \pm 12.2$ & $48.2 \pm 11.7$ \\
\hline Height $(\mathrm{Cm})$ & $139.2 \pm 12.1$ & $139.01 \pm 9.4$ & $138.2 \pm 10.8$ & $139.8 \pm 11.4$ \\
\hline $\mathrm{BMI}\left(\mathrm{Kg} / \mathrm{M}^{2}\right)$ & $23.7 \pm 3.3$ & $24.3 \pm 3.7$ & $23.8 \pm 3.1$ & $24.3 \pm 3.1$ \\
\hline Height for age (Z-score) & $0.4 \pm 0.8$ & $0.5 \pm 0.8$ & $0.5 \pm 0.9$ & $0.6 \pm 1.1$ \\
\hline Weight for age (Z-score) & $2.1 \pm 1.0$ & $2.4 \pm 1.4$ & $2.2 \pm 1.0$ & $2.4 \pm 1.0$ \\
\hline Weight for height (Z-score) & $2.9 \pm 1.1$ & $3.0 \pm 1.0$ & $2.8 \pm 0.7$ & $3.0 \pm 0.9$ \\
\hline \multicolumn{5}{|l|}{ Blood lipids: } \\
\hline $\mathrm{N}$ & 27 & 36 & 34 & 32 \\
\hline Total Cholesterol (mg/dL) & $|4| .3 \pm 3 \mid .3$ & $140.6 \pm 32.9$ & $127.4 \pm 23.3$ & $138.8 \pm 32.9$ \\
\hline Triglycerides (mg/dL) & $108.6 \pm 45.2$ & $132.2 \pm 46.4$ & $130.2 \pm 47.7$ & $125.1 \pm 45.1$ \\
\hline
\end{tabular}

* Values are means \pm standard deviation unless otherwise is mentioned.

$\uparrow$ No statistical significant difference among groups was found

Children in the RTEC and nutrition education group showed an unadjusted decrease in total body fat of 1.15 $\mathrm{kg}$ compared to the control group ( $\mathrm{p}<0.05)$ and the change adjusted for sex, school and baseline body fat was different from the control group and from the group with 1 dose or two of RTEC. Boys reduced total body fat $1.3 \%$ more than girls did $(\mathrm{p}<0.05)$ (Data not shown). Unadjusted and adjusted changes in indicators of body composition in the two RTEC groups that did not receive any nutrition education were not different compared with the control group.

The effect of different treatments on blood lipids is shown in table 4. Only children that had RTEC and nutrition education showed a significant reduction in triglycerides $(\mathrm{p}<0.05)$, an increase in HDL $(\mathrm{p}<0.01)$ and a small reduction in VLDL $(\mathrm{p}<0.05)$. Changes in the other groups were not statistically significant. Comparison of unadjusted changes among groups showed that only HDL

Table 3: Effect of treatments on anthropometry and body composition in the different groups *

\begin{tabular}{|c|c|c|c|c|}
\hline & I dose of RTEC & 2 doses of RTEC & I dose of RTEC + Nutrition education guide & Control \\
\hline$N$ & 46 & 48 & 45 & 39 \\
\hline \multicolumn{5}{|l|}{ Weight (Kg) } \\
\hline Initial & $47.0(43.0,51.1)$ & $47.7(43.6,51.8)$ & $47.0(43.2,50.8)$ & $48.2(44.04,52.3)$ \\
\hline Final & $47.92(43.9,52.0)$ & $48.6(44.6,52.7)$ & $46.08(42.5,49.7)$ & $49.30(45.2,53.4)$ \\
\hline Unadjusted change & $0.9(0.4,1.4) \ddagger$ & $0.9(0.3,1.5) \neq$ & $-0.9(-2.2,0.5) \S$ & $\mathrm{I} .2(0.8, \mathrm{I} .5) \ddagger$ \\
\hline Adjusted change $\dagger$ & $1.03(0.3,1.7)$ & $0.6(-0.1,1.3)$ & $-1.01(-1.7,-0.3) * *$ & $1.2(0.4,2.0)$ \\
\hline \multicolumn{5}{|l|}{$\mathrm{BMI}\left(\mathrm{Kg} / \mathrm{M}^{2}\right)$} \\
\hline Initial & $23.7(22.7,24.8)$ & $24.3(23.1,25.5)$ & $24.1(23.1,25.2)$ & $24.3(23.2,25.4)$ \\
\hline Final & $23.8(22.6,24.9)$ & $24.1(22.8,25.3)$ & $23.2(22.3,24.1)$ & $24.3(23.2,25.4)$ \\
\hline Unadjusted change & $0.04(-0.3,0.4)$ & $-0.2(-0.5,0.1)$ & $-1.0(-1.7,-0.2) \neq, \S$ & $0.02(-0.1,0.2)$ \\
\hline Adjusted change $\dagger$ & $0.1(-0.3,0.4)$ & $-0.3(-0.7,0.1)$ & $-0.9(-1.2,-0.5) * *$ & $0.01(-0.4,0.4)$ \\
\hline \multicolumn{5}{|l|}{ Total Body Fat (\%) } \\
\hline Initial & $23.6(20.6,26.6)$ & $25.9(22.8,28.9)$ & $24.4(21.6,27.3)$ & $27.1(23.9,30.2)$ \\
\hline Final & $24.1(20.9,27.2)$ & $25.5(22.5,28.5)$ & $23.7(20.7,26.7)$ & $27.5(24.5,30.5)$ \\
\hline Unadjusted change & $0.5(-0.1,1.1)$ & $-0.4(-1.0,0.3)$ & $-0.7(-1.7,0.3) \S$ & $0.4(-0.4,1.2)$ \\
\hline Adjusted change $\dagger$ & $0.4(-0.4,1.1)$ & $-0.5(-1.3,0.3)$ & $-0.8(-1.6,-0.04)+\dagger$ & $0.4(-0.5,1.4)$ \\
\hline
\end{tabular}

* Values are means ( $95 \%$ Confidence Interval).

† Estimated mean change adjusted for initial value, gender, school random effect and significant interactions.

fDifference between initial and final is significant at $\mathrm{p}<0.05$ in paired T-Test.

$\S$ Change is different from the control group at $p<0.05$ in ANOVA

** Estimated change from group with I dose of RTEC + Nutrition education guide is different to all other groups, at $\mathrm{P}<0.05$ in Adjusted ANOVA t† Estimated change from group with I dose of RTEC + Nutrition education guide is different to group with I dose of RTEC and to control group, at $p<0.05$ in Adjusted ANOVA 
Table 4: Effect of treatments on plasma lipids in the different groups *

\begin{tabular}{|c|c|c|c|c|}
\hline & I dose of RTEC & 2 doses of RTEC & I dose of RTEC + Nutrition education guide & Control \\
\hline $\mathrm{N}$ & 32 & 34 & 36 & 27 \\
\hline \multicolumn{5}{|l|}{ Total Cholesterol } \\
\hline Initial & I43.3 (I32.6, I54.I) & $14 \mid .3(130.0,152.7)$ & $128.6(121.1,136.1)$ & | $34.6(|23.3| 45.8)$, \\
\hline Final & $149.6(\mid 38.8,160.3)$ & $147.5(135.7,159.4)$ & $136.8(128.0,145.6)$ & |4|.3 (I32.0, I50.7) \\
\hline Unadjusted change & $6.2(-7.3,19.7)$ & $6.2(-8.0,20.4)$ & $8.2(-3.4,19.8)$ & $6.7(-5.8,19.3)$ \\
\hline Adjusted change $\dagger$ & $14.7(4.5,24.9)$ & $14.2(4.3,24.1)$ & $9.5(-0.7,19.6)$ & $6.2(-4.7,17.1)$ \\
\hline \multicolumn{5}{|l|}{ Triglycerides } \\
\hline Initial & $109.5(92.9,126.1)$ & I34.2 (I I8.I, I50.2) & $129.5(113.4,145.6)$ & $121.9(106.6,137.1)$ \\
\hline Final & $134.5(109.7,159.2)$ & I 19.4 (102.9, 135.8) & $108.7(92.8,124.6)$ & $121.6(102.2,141.0)$ \\
\hline Unadjusted change & $25.0(-3.6,53.6)$ & $-\mid 4.8(-3 \mid .8,2.2)$ & $-20.7(-36.4,-5.1) \neq$ & $-0.2(-19.3,18.8)$ \\
\hline Adjusted change $†$ & $13.5(-6.5,33.4)$ & $-10.3(-29.0,8.4)$ & $-18.1(-36.7,0.6)$ & $-4.3(-24.6,16.0)$ \\
\hline \multicolumn{5}{|l|}{ HDL cholesterol } \\
\hline Initial & $48.4(43.9,52.8)$ & $48.1(44.3,51.8)$ & $43.1(39.3,47.0)$ & $47.5(42.4,52.6)$ \\
\hline Final & $47.0(42.4,51.6)$ & $48.5(44.8,52.2)$ & $49.7(46.5,53.0)$ & $44.8(40.5,49.1)$ \\
\hline Unadjusted change & $-1.4(-7.3,4.6)$ & $0.4(-4.6,5.5)$ & $6.6(2.2,11.1) \ddagger, \S$ & $-2.7(-6.5, I . I)$ \\
\hline Adjusted change $\dagger$ & $-2.2(-5.7,1.4)$ & I.0 $(-2.4,4.3)$ & I.7 $(-1.7,5.1)$ & $-3.0(-6.7,0.7)$ \\
\hline \multicolumn{5}{|l|}{ LDL cholesterol } \\
\hline Initial & $122.6(111.0,134.3)$ & $123.6(112.2,135.1)$ & II4.I (104.9, I23.4) & I I $6.7(106.7,126.8)$ \\
\hline Final & $137.1(123.5,150.6)$ & $125.2(112.9,137.5)$ & II $2.3(101.3,123.2)$ & $125.4(114.4,136.4)$ \\
\hline Unadjusted change & $14.4(1.0,27.8) \ddagger$ & $1.6(-|| .8, \mid 4.9)$ & $-1.9(-15.7,12.0)$ & $8.7(-5.0,22.3)$ \\
\hline Adjusted change $\dagger$ & $19.3(7.3,31.3)$ & $9.2(-2.3,20.7)$ & $1.8(-10.0,13.5)$ & $8.0(-4.8,20.8)$ \\
\hline \multicolumn{5}{|l|}{ VLDL cholesterol } \\
\hline Initial & $21.9(18.6,25.2)$ & $26.8(23.6,30.0)$ & $25.7(22.6,28.9)$ & $24.4(21.3,27.4)$ \\
\hline Final & $26.9(22.0,31.9)$ & $23.9(20.6,27.2)$ & $21.9(18.8,25.1)$ & $24.3(20.5,28.2)$ \\
\hline Unadjusted change & $5.0(-0.7,10.7)$ & $-3.0(-6.4,0.5)$ & $-3.8(-6.9,-0.6) \neq$ & $-0.04(-3.9,3.8)$ \\
\hline Adjusted change $\dagger$ & $2.6(-1.4,6.6)$ & $-2.0(-5.8,1.7)$ & $-3.3(-7.0,0.4)$ & $-0.8(-4.9,3.2)$ \\
\hline
\end{tabular}

* Values are means $(95 \% \mathrm{Cl})$ in $\mathrm{mg} / \mathrm{dL}$.

† Estimated mean change adjusted for initial value, gender, school random effect and significant interactions.

¥ Difference between initial and final significant at $p<0.05$ in paired T-test.

$\S$ Change in group with I dose of RTEC + Nutrition education guide is different to change in group with I dose of RTEC and to the control group at $p<0.01$ in ANOVA.

increased significantly in the group with RTEC and nutrition education compared to the control group. Treatment changes adjusted for baseline value and school were not different from the control group.

Changes \pm standard deviation (SD) in intense, moderate and low physical activities in Mets/week were the following: for with 1 dose of RTEC, $13.4 \pm 41.3,4.3 \pm 12.7,3 \pm$ 18 , for group with 2 doses of RTEC $2.4 \pm 61.5,-2.2 \pm 17.1$, $2.6 \pm 31.9$, for with 1 dose of RTEC + education guide -3.6 $\pm 52.4,-0.2 \pm 16,-5 \pm 19$ and for the control group $4.6 \pm$ $31.6,-1.1 \pm 9.9,6.7 \pm 18.5$. Changes were not statistically different neither between basal and final evaluations nor among experimental groups. When adjusting model for gender and school, boys increased their intense physical activity while girls decreased it resulting in a significant difference between boys and girls $(8.8 \pm 60.2$ vs $12.6 \pm$ 85.7).

\section{Discussion}

Although there are many environmental factors promoting excess energy intake, consumption of high fat diets increases the likelihood of obesity and the risk of obesity is lower in individuals consuming low fat diets. A review of clinical trials and animal studies [22] suggests that the Public Health recommendation to lower dietary fat intake continues to be an appropriate measure to reduce energy intake and obesity. Fat compared with carbohydrates and proteins, increases the energy density of foods and diets.. Thus, a logical suggestion has been to replace fat with carbohydrate and therefore, decrease the energy density of the diet [5].

The present study showed that the increase in RTEC consumption as a source of carbohydrate in children was effective in reducing body weight and body fat only when a nutrition education guide was included as part of the treatment. The inclusion of either one or two servings of RTEC in the diet without nutrition education was not effective in reducing body fat and did not cause any significant change in body weight compared with the control no-treatment group. Kirk et al [5] found a significant reduction of $2 \mathrm{~kg}$ body weight in 29 adults that replaced one meal with a serving of RTEC everyday during 4 weeks as a high carbohydrate regime. Differences between our study and this study include the difference in the popula- 
tion studied but more important is that the study by Kirk et al [5] did not include a control group. This makes its conclusion about the effectiveness of increasing carbohydrate consumption as an effective approach to treat obesity weak. Rodearmel et al. [23] studied the impact of increasing 2 serving of RTEC/day and increasing daily steps in a 13-week intervention study as a family-based approach to prevent obesity and found significant differences in children's BMI-for-age and body fat between the experimental and the control groups. The control group in this study did not receive any intervention, therefore, the effect of the RTEC seen cannot be separated from the increase in physical activity in the children.

Our study agrees with other studies $[5,23]$ in the fact that an increase in RTEC consumption as a source of carbohydrates was shown to be an effective strategy to lose weight in obese children but our study suggests that only when it is given with nutrition education. The change in body weight in the group receiving education and RTEC was accompanied with a reduction in total body fat. These changes did not occur in the groups that received one or two servings of RTEC and that the mother and child did not receive any nutrition education guide. These findings suggest that in our population a nutrition education guideline might be necessary for the beneficial effects of increasing carbohydrate consumption.

The importance of education programs in the treatment of obesity has been known for a number of years, but only recently it has been suggested that nutrition education should be part of any successful strategy to reduce obesity in children [24-29], adolescents [27-30] and in adults [31,32]. Also, nutrition education has proven to be effective in improving nutritional status of individuals in different populations at risk. Studies of nutrition education programs that are continuous, specific, focused and targeted to vulnerable populations have been successful in improving nutritional status [33-37]. Our study suggests that providing a nutrition education guide makes dietary changes, such as increase in carbohydrate consumption, more effective, and that a lack of an adequate nutritional education can cause nutritional strategies to fail.

It is important to consider that since we did not include a group receiving nutrition education alone, we are unable to conclude that the group receiving RTEC in addition to a nutrition education program works any better than nutrition education alone to increase carbohydrate intake. The study was not designed to test the effect of a nutrition education program without the increase in RTEC consumption.

The reduction in body fat and body weight in the RTEC and nutrition education group of the children was accom- panied by a significant reduction in plasma triglycerides and by an elevation in HDL. Changes in these two variables are clearly associated with a reduction in body fat and are beneficial to reduce health complications associated with excess of body fat.

\section{Conclusion}

We found that a strategy to increase carbohydrate consumption to reduce obesity in children is effective only when accompanied with a nutrition education program. An increase in RTEC intake as a source of carbohydrates with a simple nutrition education guideline produced a significant loss of body weight, a decrease in body fat and in plasma triglycerides, and an increase in high density lipoproteins. The importance of nutrition education could be extrapolated to other nutritional manipulations intended for treatment of obesity.

\section{Consent}

Written informed consent was obtained from the parents for participation and publication of results. A copy of the written consent is available for review by the Editor-inChief of this journal. This study was approved by the Internal Committee of Human Research of the University of Queretaro.

\section{Competing interests}

The authors declare that they have no competing interests.

\section{Authors' contributions}

JLR developed the study design, supervised the study, and made a substantial contribution with interpretation of data, drafting the manuscript and revising it critically for important intellectual content. MRA participated in the study design and coordinated the field research. KM coordinated the field research and supervised the quality of data collection. OPG contributed with the study conception and design, interpretation of data and writing the publication. And MCC participated in managing the data, carried out the statistical analysis and contributed to revising the manuscript. All authors read and approved the final manuscript.

\section{Acknowledgements}

We would like to thank Juana Ramirez Anguiano, Paola García Juarez and Abigail Dominguez Chavero for their dedicated work, and to Elba Suaste for her special touch when taking blood from children and her assistance with laboratory work. We are grateful to Kellogg Company México S.A de C.V. that contributed with a scientific grant for partial funding of the study.

\section{References}

I. De-Onis $M$, Blössner $M$ : Prevalence and trends of overweight among pre-shoolchildren in developing countries. $\mathrm{Am} \mathrm{J} \mathrm{Clin}$ Nutr 2000, 72: 1032-9.

2. Olaiz-Fernandez G, Rivera-Domarco J, Shama-Levy T, Rojas R, Villalpando-Hernández S, Hernández-Ávila $H$, Sepúlveda-Amor J: Encuesta Nacional de Salud y Nutricion 2006. Cuernavaca, Mexico: Instituto Nacional de Salud Pública; 2006. 
3. Velazquez-Monroy O, Rosas-Peralta M, Lara-Esqueda A: Prevalenciae interrelación de enfermedades crónicas no transmisibles y factores de riesgo cardiovascular en México: Resultados finales de la Encuesta Nacional de Salud (ENSA). Archivo de cardiología de México 2003, 72(I):71-84.

4. Encuesta Nacional de Enfermedades Crónicas (ENEC). Book Encuesta Nacional de Enfermedades Crónicas (ENEC) (Editor ed.^^eds.). City: Secretaría de Salud 1993.

5. Kirk T, Crombie N, Cursiter M: Promotion of dietary carbohydrate as an approach to weight maintenance after initial weight loss: A pilot study. J Hum Nutr Dietet 2000, 13:277-285.

6. Jeffrey RW, Hellerstedt WL, French SA, Baxter IE: A randomized trial of counsselling for fat restriction versus caloric restriction in the treatment of obesity. Obesity 1995, 19:132-137.

7. Astrup A, Ryan L, Grundwald G, Saris W, Hill W: Ad libitum low fat diets and body fatness: a meta-analysis of intmention studies. BrJ Nutr 2000, 83(SuppI I):S25-S32.

8. Lyon XH, Di-Vetta V, Milon H, Jequier E, Schutz Y: Compliance to dietary advise directed towards increasing the carbohydrate to fat ratio of the everyday diet. Intl I Obesity 1995, 19:260-269.

9. Holmes $\mathrm{KW}$, Kwiterovich PO Jr: Treatment of dyslipidemia in children and adolescents. Curr Cardiol Rep 2005, 7:445-56.

10. Reinehr T, Roth CL, Alexy U, Kersting M, Kiess W, Andler W: Ghrelin levels before and after reduction of overweight due to a low-fat high-carbohydrate diet in obese children and adolescents. Int J Obes 2005, 29:362-8.

II. Rolls BJ: The role of energy density in the overconsumption of fat. J Nutr 2000, 130:268S-27IS.

12. Kirk TR, Burkill S, Cursiter M: Dietary fat reduction achieved by increasing consumption of a starchy food - an intervention study. Eur J Clin Nutr 1997, 5 I:

13. Crombie N, Kirk T: Prevention of weight gain and blood cholesterol reduction after consumption of a high carbohydrate food in men. Int/ I Obesity 1999, 23:557.

14. Kuczmarski RJ, Ogden CL, Grummer-Strawn LM, Flegal KM, Guo SS, Wei R, Mei Z, Curtin L, Roche AF, Johnson CL: CDC growth charts: United States. In Book CDC growth charts: United States. (Editor ed.^eds.) City: National Center for Health Statistics; 2000.

15. A Pérez-Lizaur, Marvan A: Manual de documentos normales y terapéuticos. 3a edition. México: Edit. Manual Moderno; 1996

16. Physical growth and psychosocial development of children: monitoring and interventions, protocols $\mathrm{I}$ and II, the development and field testing of techniques for monitoring. In Book Physical growth and psychosocial development of children: monitoring and interventions, protocols I and II, the development and field testing of techniques for monitoring. (Editor ed.^eds.) City: World Health Organization. Maternal and child health and family planning unit; 1992.

17. Hernández B, Gortmaker SL, Laird N, Colditz G, Parra-Cabrera S, Peterson K: Validez y reproducibilidad de un cuestionario de actividad e inactividad física para escuelas de la Ciudad de México. Salud Pública de México 2000, 42:3I5-323.

18. Ainsworth B: Compendium of physical activities tracking guide. In Book Compendium of physical activities tracking guide. (Editor ed.^eds.) City: Prevention Research Center, Norman J Arnold School of Public Health, University of South Carolina; 2002.

19. Kotler DP, Burastero S, Wang J, Jr RNP: Prediction of Body Cell Mass, Fat-Free Mass, and Total Body Water with Bioelectrical Impedance Analysis: Effects of Race, Sex, and Disease. Am J Clin Nutr 1996, 64:489S-97S.

20. Bachorick PS, Levy RI, Rifkind BM: Lípidos y dislipoproteinemia. In Diagnóstico y tratamiento clínicos por el laboratorio 9 a edition. Edited by: Henry JB. Barcelona: Masson S A; 1993:195-221.

21. Snedecor GW, Cochran WG: Statistical methods. 7a edition. lowa State: University Press; 1987.

22. Hill JO, Melanson EL, Wyatt HT: Dietary fat intake and regulation of energy balance: Implications for obesity. J Nutr 2000, 130:284S-288S.

23. Rodearmel SJ, Wyatt HT, Barry MJ, Dong F, Pan D, Israel RG, Cho SS, McBurney MI, Hill JO: A family-based approach to preventing excessive weight gain. Obesity 2006, I4:1392-I40I.

24. Epstein LH, Roemmich JN, Raynor HA: Behavioral therapy in the treatment of pedriatic obesity. Pediatr Clin North Am 200I, 48:98I-93.

25. Barlow SE, Dietz WH: Management of child and adolescent obesity: Summary and recommendations vased on reports from pediatricians, pediatric nurse practitioners, and registered dietitians. Pediatrics 2002, I I 0:236-38.

26. Kain J, Uauy R, Albala , Vio F, Cerda R, Leyton B: School-based obesity prevention in Chilean primary school children: Methodology and evaluation of a controlled study. Int Obes Relat Metab Disord 2004, 28:483-93.

27. Dietz WH, Gortmaker SL: Preventing obesity in children and adolescents. Annu Rev Public Health 200I, 22:337-53.

28. Birch LL, Davison KK: Family environmental factors influencing the developing behavioral controls of food intake and childhood overweight. Pediatr Clin North Am 200I, 48:893-907.

29. Deckelbaum RJ, Williams CL: Childhood obesity: The health issue. Obesity Research 200I, 9:239S-243S.

30. Stettler N: Environmental factors in the etiology of obesity in adolescents. Ethn Dis 2002, 1 2:4I-5.

31. Crawford PB, Gosliner W, Anderson C, Strode P, Becerra-Jones Y, Samuel S, Carroll AM, Ritchie LD: Counceling latina mothers of preschool children abount weight issues: Suggestions for a new framework. J Am Diet Assoc 2004, 104:387-94.

32. McCrory MA, Suen VMM, Roberts SB: Biobehavioral influences on energy intake and adult weight gain. J Nutr 2002, 132:3830S-3834S.

33. Bhandari N, Mazumder S, Bahl R, Martines J, Black R, Bhan M, et al: An educational intervention to promote appropriate complementary feeding practices and physical growth in infants and young children in rural Haryana, India. J Nutr 2004, 134:2342-48.

34. Bronner Y, Hawkins AS, Holt ML, Hossain MB, Rowel RH, Sydnor KL, Divers SP: Models for nutrition education to increase consumption of calcium and dairy products among African Americans. I Nutr 2006, I36: I 103-6.

35. Creed-Kanashiro H, Uribe T, Bartolini R, Fukumoto M, Lopez T, Zavaleta $N$, Bentley $M$ : dietary intake to prevent anemia in adolescent girls through community kitchens in a periurban population of Lima, Peru. J Nutr 2000, I30:459s-46 Is.

36. Guldan G, Fan H, Ma X, Ni Z, Xiang X, Tang M: Culturally appropriate nutrition education improves infant feeding and growth in rural Sichuan, China. J Nutr 2000, 130:1204-I2II.

37. Hunt IF, Jacob M, Ostergard NJ, Masri G, Clark VA, Coulson AH: Effect of nutrition education on the nutritional status of lowincome pregnant women of Mexican descent. Am J Clin Nutr 1976, 29:675-684.

Publish with Bio Med Central and every scientist can read your work free of charge

"BioMed Central will be the most significant development for disseminating the results of biomedical research in our lifetime. "

Sir Paul Nurse, Cancer Research UK

Your research papers will be:

- available free of charge to the entire biomedical community

- peer reviewed and published immediately upon acceptance

- cited in PubMed and archived on PubMed Central

- yours - you keep the copyright 